\title{
Histological prognostic factors in children with Henoch Schönlein Purpura nephritis
}

Jean-Daniel Delbet ${ }^{1,2}$, Guillaume Geslain ${ }^{1}$, Martin Auger ${ }^{1}$, Julien Hogan ${ }^{3,4}$, Rémi Salomon ${ }^{5}$, Michel Peuchmaur ${ }^{3}$, Georges Deschênes ${ }^{3,4}$, David Buob ${ }^{6}$, Cyrielle Parmentier ${ }^{1}$, Tim Ulinski ${ }^{1,2}$,

${ }^{1}$ Pediatric Nephrology, Armand Trousseau Hospital, APHP, Paris, France

${ }^{2}$ University Pierre and Marie Curie, Paris 6, Paris, France

${ }^{3}$ Pediatric Nephrology, Robert Debré Hospital, APHP, Paris, France

${ }^{4}$ University Paris Diderot. Paris 7, Paris, France

${ }^{5}$ Pediatric Nephrology, Necker Enfants Malades, APHP, Paris, France

${ }^{6}$ Pathology Department, Tenon Hospital, APHP, Paris, France

Corresponding author

Jean-Daniel Delbet, MD

Department of Pediatric Nephrology,

Armand Trousseau Hospital

26 Avenue du Docteur Arnold Netter, 75012 Paris, France

Tel: +33-144736662; Fax: +33-144736663

Email: jean-daniel.delbet@.aphp.fr

Keywords: Henoch-Schonlein purpura nephritis, IgA vasculitis with nephritis, renal outcomes, pediatric, histological prognostic factors 


\section{Abstract}

Introduction. The management of IgA vasculitis with nephritis (IgAVN) remains controversial because of the difficulty to identify prognostic factors. This study reports the prognosis of children with IgAVN in relation to histological parameters.

Methods. All children with IgAVN diagnosed between 2000 and 2015 in three pediatric nephrology centers were included. The following histological parameters were analyzed: mesangial proliferation (MP), endocapillary proliferation (EP), crescents, active or chronic tubular and interstitial lesions (TIa lesions / TIc lesions), and segmental glomerulosclerosis (GS). Clinical and biological data were collected at the time of renal biopsy. The primary endpoint was IgAVN remission defined as a proteinuria $<200 \mathrm{mg} / \mathrm{L}$ without renal failure.

Results. 159 children were included with a median age of 7.6 years. Acute glomerular or TI lesions including MP, EP, crescents, and TIa lesions were observed, respectively, in 81\%, $86 \%$, $49 \%$, and $21 \%$ of patients. Chronic glomerular lesions including GS and TIc lesions were observed in 6 and $7 \%$ of patients. Median initial proteinuria was $330 \mathrm{mg} / \mathrm{mmol}$, albuminemia $32 \mathrm{~g} / \mathrm{l}$, and eGFR $110 \mathrm{ml} / \mathrm{min} / 1.73 \mathrm{~m}^{2} .112$ (70\%) patients were in remission at the end of a median follow up of 37.4 months. Chronic lesions were significantly associated with the absence of remission in multivariate analysis, whereas EP, crescents and TIa were not associated with a poor prognosis.

Conclusion. 30\% of children with IgAVN present a persistent renal disease at the end of a 3year follow-up. Chronic histological lesions, but not EP or crescents are associated with a bad prognosis and must be evaluated in IgAVN histological classification. 


\section{Introduction}

IgA vasculitis (IgAV) or Henoch-Schönlein purpura (HSP) is one of the most common causes of systemic vasculitis in children. The long-term prognosis is dependent on renal involvement. IgAV with nephritis (IgAVN) occurs in about one third of IgAV patients [1]. The risk of progression to renal failure is estimated from $2 \%$ [2], to $20 \%$ in specialized centers [3]. Even if poor prognosis seems to be linked to severe initial clinical or histological presentation, a poor outcome may occur even in patients with isolated hematuria or mild proteinuria at disease onset [4,5]. Thus, the individual prognosis of IgAVN is difficult to establish and its management remains controversial.

The widely used International Study of Kidney Disease in Children (ISKDC) classification for IgAVN is mainly based on the presence of crescents and it does not completely correlate with the clinical presentation and long-term prognosis of IgAVN. This might explain partially why many authors did not identify histological markers as a prognostic factor $[3,6,7]$.

We know that IgAVN and IgA Nephropathy (IgAN) have many similarities in terms of clinical presentation and pathophysiology [8]. The Oxford Classification assesses lesions depending on the presence of mesangial hypercellularity, glomerulosclerosis (GS), endocapillary proliferation (EP) or interstitial fibrosis and tubular atrophy (IF/TA). These histological characteristics are now recognized as prognostic factors in IgAN [9]. In 2014, a first evaluation of the Oxford Classification in IgAVN in adults showed that EP and IF/TA lesions were associated with long-term renal function impairment [10].

In view of these results, it seems interesting to analyse more histological parameters in IgAVN long-term prognosis. The aim of this study was to evaluate renal prognosis in children with IgAVN and to analyze the relation to clinical and histological prognostic factors at disease onset and the chosen treatment. 


\section{Method}

We performed a retrospective multicenter study in the pediatric nephrology units of Armand Trousseau Hospital, Robert Debré Hospital and Necker Enfant Malades Hospital from 2000 to 2015.

\section{Patients}

All patients from 1 to 18 years at disease onset, with a clinical diagnosis of IgAV according to criteria defined by the American College of Rheumatology [11], with a diagnosis of IgAVN including renal biopsy with histological prove of predominant mesangial IgA immune deposits and with a minimal follow-up of six months were considered for inclusion.

All biopsy specimens were examined by light microscopy and immunofluorescence microscopy.

Histological parameters were extracted from the original histopathological report for each renal specimen.

Histological parameters were defined as follows:

'MP or hypercellularity’ was defined as equal to or greater than four mesangial cells in any mesangial area and more than $50 \%$ of glomeruli with mesangial hypercellularity. The category 'EP' was defined by the presence of EP in at least one glomerulus. The category 'GS' was defined by the presence of GS in at least one glomerulus. The category 'IF/TA' was defined by more than $25 \%$ of cortical area affected by tubular atrophy and/or interstitial fibrosis. The category 'cellular crescents' was defined by the presence of at least one cellular crescent. The category 'fibrous crescents' was defined by the presence of at least one fibrous crescent.

Fibrous crescents, GS, IF/TA were reported and defined as chronic lesions. Cellular or fibrocellular crescents, EP and inflammatory tubulointerstitial lesions were reported and defined as 
acute lesions. Inflammatory tubulointerstitial lesions include interstitial mononuclear infiltrate, interstitial edema, and acute tubular damage.

\section{Clinical and biological features}

At the time of renal biopsy, clinical and biological data were evaluated: serum creatinine, total protein, albumin, and proteinuria were collected. Nephrotic syndrome (NS) was defined as albumin $<25 \mathrm{~g} / \mathrm{L}$ in association with nephrotic proteinuria (urine protein/creatinine ratio $>250$ $\mathrm{mg} / \mathrm{mmol}$ or 24 -h protein $>50 \mathrm{mg} / \mathrm{kg} / 24 \mathrm{H}$ ). A nephrotic range proteinuria was defined as a proteinuria $>250 \mathrm{mg} / \mathrm{mmol}$ without hypoalbuminemia and a significant proteinuria was defined by a proteinuria between $20 \mathrm{mg} / \mathrm{mmol}$ and $250 \mathrm{mg} / \mathrm{mmol}$. Hypertension was defined as average systolic or diastolic blood pressure greater than or equal to the 95th percentile for age, gender, and height. The 2009 Schwartz formula was used to estimate glomerular filtration rate (eGFR) from the serum creatinine and height. Demographic characteristics collected from the medical history such as gender, age at onset, and age at biopsy were collected.

The onset of renal involvement in IgAV was defined as discovery of hematuria and/or proteinuria on dip stick.

\section{Treatment}

Treatment modalities were collected and summarized in six groups: no immunosuppressive treatment, oral corticosteroids alone, angiotensin-converting enzyme inhibitors and angiotensin receptor blockers (ACEi/ARBs) alone, oral corticosteroids and ACEi/ARBs, methylprednisolone pulse therapy followed by oral corticosteroids, or other immunosuppressive therapy. 
Despite slight differences among the three centers, the basic modality for steroid pulses was 1 $\mathrm{g} / 1.73 \mathrm{~m}^{2}$ on day 1,3 , and 5 . Oral prednisone was given at a dosage of $2 \mathrm{mg} / \mathrm{kg}$ per day for 30 days, followed by a tapering down over the three following moths with a cumulative prednisone dose of $3900 \mathrm{mg} / \mathrm{m}^{2}$.

Monitoring and endpoint

Patients’ data were recorded until their last documented outpatient visit.

The primary endpoint was IgAVN remission defined by negative proteinuria $(<20 \mathrm{mg} / \mathrm{mmol}$ of urinary creatinine) and a GFR $>90 \mathrm{ml} / \mathrm{min} / 1.73 \mathrm{~m}^{2}$ during the follow-up.

\section{Statistical analysis}

Quantitative variables are presented as median and interquartile and qualitative variables as percentages. Dichotomous variables were compared using the chi-squared test. For all continuous variables, if the Shapiro-Wilk test revealed a non-normal distribution, the Rank Sum Test was used, if the Shapiro-Wilk test revealed a normal distribution, student test were used. $p$ value $<0.05$ were considered significant.

Logistic regression models were used to study the association between the patient characteristics and outcome. For multivariate analysis, the primary endpoint was IgAVN remission one year after the diagnosis. We first performed univariable logistic regressions on all the patient characteristics to determine which ones to include in our final models. All variables with a P-value greater than 0.2 were included in the multivariable logistic regression models All continuous variables were tested for linearity with the SAS macro LGTPHCURV9. All tests were performed at an $\alpha$-risk value of 0.05. Statistical analysis was performed with SAS 9.2. 


\section{Results}

Baseline patients' characteristics

A total of 159 patients with a diagnosis of IgAVN followed for a minimum of six months were included.

Among these 159 patients, there were 85 boys and 74 girls (sex ratio 0.88), the median age at the time of renal biopsy was 7.6 years (5.8-9.5). The median duration from the time of HSP diagnosis to renal involvement (discovery of hematuria and/or proteinuria on dip stick) was 17 days (6-32). 113 (71\%) developed renal involvement within 30 days after the HSP onset, 36 (23\%) between day 31 and day 180 and 2 (1\%) between day 180 and the end of the first year. Eight patients developed a renal involvement more than one year after their first HSP clinical manifestation. The median duration from the renal involvement and the renal biopsy was 21 (10-39) days.

The median eGFR was $110 \mathrm{ml} / \mathrm{min} / 1.73 \mathrm{~m}^{2}$ (87.9-130.4), 9 children (5\%) had a GFR <60 $\mathrm{ml} / \mathrm{min} / 1.73 \mathrm{~m}^{2}$, 33 (21\%) a GFR between 60 and $90 \mathrm{ml} / \mathrm{min} / 1.73 \mathrm{~m}^{2}$ and 117 (74\%) a GFR $>90 \mathrm{ml} / \mathrm{min} / 1.73 \mathrm{~m}^{2}$.

The median initial proteinuria was $2820 \mathrm{mg} / \mathrm{L}$ (1440-5000), with a median proteinuria/creatininuria ratio of $330 \mathrm{mg} / \mathrm{mmol}(180-630)$ and median serum albumin of 32 g/L (27-37). At the time of the renal biopsy, 31 patients (19\%) had a NS, 51 (32\%) patients had a nephrotic range proteinuria and 77 (48\%) patients had a significant proteinuria.

31 (19\%) patient had a blood pressure above the $95^{\text {th }}$ percentile at diagnosis. $128(80 \%)$ patients had no high blood pressure.

\section{histological patients' characteristics}

Per kidney biospsy, a median number of 17 glomeruli could be assessed (IQR 13-24), 8 biopsies has less than 7 glomeruli and 8 biopsies had between 7 and 10 glomeruli. 
Histological findings revealed mesiangial IgA deposits in all patients. Glomerular crescents in 80 biopsies (50\%), and 16 patients has more than 50\% of glomeruli with crescents. Only 5 (3\%) patients had fibrous crescents.

Mesangial proliferation was present on 129 biopsies (81\%) and EP was present on 136 biopsies (86\%). GS was present on 10 and IF/TA on 12 biopsies: in total, 19 patients had chronic lesions. 34 patients had interstitial mononuclear infiltrate, interstitial edema, and tubular damage.

\section{Treatment}

Oral steroid therapy was administered in 141 patients (88\%) and a median dose of 3990 $\mathrm{mg} / \mathrm{m}^{2}$ (3990-4200). 31 (19\%) patients received oral steroids alone and 81 patients received three methylprednisolone pulses followed by oral corticosteroids. 18 patients (11\%) did not receive steroids. 14 patients received other immunosuppressive treatments including azathioprine and cyclophosphamide. Treatment with ACEi/ARBs was administered in 119 patients (75\%) for a median of 445 days (157 to 1156). 9 (6\%) patients received ACEi/ARBs alone and 110 (69\%) patients received ACEi/ARBs and oral steroids.

These results are presented in Table 1.

\section{Follow-up results}

Patients were followed for a median time of 37.4 months (20-76). Overall, 112 patients (70\%) were in remission after 175 days (97.5-335). At last follow up, the median eGFR was 110.5 $\mathrm{mL} / \mathrm{min} / 1.73 \mathrm{~m}^{2}$ (91.9-127.6), no patient had a GFR $<60 \mathrm{ml} / \mathrm{min} / 1.73 \mathrm{~m}^{2}$ except two patients with a renal transplantation.

47 (30\%) patients were not in remission. At the end of the follow-up, 19 patients (12\%) of the cohort had an eGFR $<90 \mathrm{ml} / \mathrm{min} / 1.73 \mathrm{~m}^{2}$ and 79 (50\%) patients had no assessment of renal 
function. Nine patients had an eGFR $<90 \mathrm{ml} / \mathrm{min} / 1.73 \mathrm{~m}^{2}$ without proteinuria. Two patients had a kidney transplant, the first patient was 6 years old at diagnosis; he had a nephrotic syndrome with a renal failure $\left(\mathrm{eGFR}=37 \mathrm{ml} / \mathrm{min} / 1.73 \mathrm{~m}^{2}\right)$ and on renal biopsy $70 \%$ of glomeruli with crescents without chronic lesions. The other one was 12 years old, with nephrotic proteinuria, without hypoalbuminemia and a mild renal failure $\left(\mathrm{eGFR}=77 \mathrm{ml} / \mathrm{min} / 1.73 \mathrm{~m}^{2}\right)$. He also had crescents in $30 \%$ of glomeruli

At last follow-up, among these 47 patients who were not in remission, the median eGFR was $89.1 \mathrm{~mL} / \mathrm{min} / 1.73 \mathrm{~m}^{2}(79.4-122.1)$ and the median proteinuria/creatininuria ratio was 40 $\mathrm{mg} / \mathrm{mmol}(20-85)$.

\section{Clinical and therapeutic prognosis factors}

Patients in remission were significantly younger than patients not in remission 7.2 vs. 8.4 $(p=0.003)$. Initial eGFR of patients not in remission was significantly lower than that of patients in remission (99.9 vs. 115; $\mathrm{p}=0.02$ ) and patients not in remission received significantly more ACE inhibitors whether alone (91\% vs. $68 \%$; $\mathrm{p}=0.001)$ or in association with steroids ( $63 \%$ vs $82 \%$; $\mathrm{p}=0.015$ ) than patients in remission. The proportion of patients who received steroids alone was significantly higher in patients in remission than in patients not in remission ( $26 \%$ vs. $4 \%$; $\mathrm{p}=0.002)$. There was no statistically significant difference between patients in remission and patients not in remission in terms of gender, duration between diagnosis of HSP and nephritis, duration between the diagnosis of nephritis and kidney biopsy, proteinuria and steroid treatment. These results are presented in Table 2.

\section{Histological prognostic factors}

There was no statistically difference in terms of presence of EP, cellular crescents or acute tubulointerstitial lesions between the patients in remission vs. patients not in remission. Patients in remission had significantly less GS $(\mathrm{p}=0.028)$, AT/FI $(\mathrm{p}=0.09)$ and chronic lesions 
$(p=0.01)$ than patients not in remission in univariate analysis. These results are presented in Table 3.

Patients with chronic lesions have a significant longer delay between IgAVN diagnosis and biopsy than patients without chronic lesions, (48 vs. 21 days; $\mathrm{p}=0.046$ ). The delay between IgAVN diagnosis and biopsy for each patient is shown in Figure 1. There was no difference in terms of age, delay between HSP diagnosis and renal involvement, eGFR, proteinuria, and treatment between patients with chronic lesions and patients without chronic lesions. These results are shown in Table 4.

In univariate analysis, there was no difference in terms of crescents and EP between the two groups ( $p=0.71$ and $p=0.46$ respectively). The level of initial proteinuria was similar in the two groups $(p=0.56)$. The delay between renal involvement and biopsy and the proportion of chronic lesions were significantly higher in patients not remission ( $p=0.03$ and $p=0.005$ respectively).

In multivariate analysis, chronic lesions were significantly associated with the absence of remission one year after IgAVN diagnosis: odds ratio: 3,84 with 95\% confidence interval (1.118-12.445). These results are shown in Table 5.

\section{Discussion}

In this retrospective study, we analysed renal prognosis in children with kidney biopsies for IgAVN since 2000. Overall 112 patients out of 159 were in remission at the end of a followup of 37 months. This show, that almost one third of pediatric patients presented a chronic renal disease 3 years after IgAVN onset. This result is similar to historical series: in 1992, Goldstein et al reported persistent kidney disease in 35\% of 78 patients [12] after a follow-up of 23.4 years and in 1997 Coppo et al reported an absence of remission in 30\% of patients after 4.8 years [6]. More recent studies have also found the same proportion of persistent 
kidney disease: in 2005, among 78 patients included in the study of Halling et al, 26\% had persistent renal disease after 5.2 years [13] and in 2007, Mir et al found 77\% of favorable outcome among 141 children after 8.9 years [14]. IgAVN is generally recognized as an acute disease with a good prognosis, but a large proportion of children was still proteinuric three years after initial diagnosis. Considering that proteinuria is due to hyperfiltration lesions secondary to nephron loss, we can suppose that the proportion of patients with proteinuria may still increase in adulthood.

Our median number of glomeruli was 17; only 15 biopsies out of 159 had a number of glomeruli under 10, which is similar to what has been reported in the Oxford classification report [15]. We can consider that theses kidney samples were sufficient for histological analysis.

Acute histological lesions like EP, mesangial proliferation, acute tubulointerstitial lesions, and cellular crescents were represented in a great proportion of our analysed biopsies. On the other hand, chronic lesions such as GS, IF/TA or fibrous crescents were very rare in our sample.

Nevertheless, the presence of chronic lesions was associated to the probability of persistent renal disease in multivariate analysis. The link between chronic lesions at diagnosis and persistent proteinuria during follow-up is not surprising and has been found in another previous study. These lesions should be evaluated in IgAVN histological analysis and should not be ignored in IgAVN histological classification. Therefore, we included in our histological classification all types of chronic lesions such as IF/TA, fibrous crescents, and GS, which are not part of ISKDC classification.

However, it is not clear in which circumstances this kind of lesions appear.

In our study, like in another German study concerning IgAVN histological features [16], a longer delay between nephritis and kidney biopsy was related with a higher proportion of 
chronic lesions. Not surprisingly, longer delay after initial inflammation produces more sclerosis or fibrosis. Therefore, these results are very important for the clinician: following KDIGO guidelines, in patients with persistent proteinuria without renal failure (which is a large proportion of patients with IgAVN) no steroid treatment is recommended, which increases the risk to transform acute lesions into chronic lesions [17]. Furthermore, it has been shown that chronic lesions are insensitive to immunosuppressive therapy [18]. Therefore, it may be dangerous to delay steroid treatment in these patients as suggested in a recent review paper commenting these guidelines [19].

Another possible explanation for a high proportion of chronic lesions is patient age. Indeed, adult IgAVN patients have a higher proportion of chronic histological lesions: recently Kim et al studied 61 biopsy-proven patients with IgAVN. About one third of their patients had chronic lesions while only 15\% of them had EP [20] and Inagaki et al studied the biopsy of 74 patients with IgAVN: GS was present in 50\% of patients [21]. Even in children, the difference of histological features depending on patient age was highlighted: These authors found that younger patients had less often GS or chronic lesions on their initial biopsy [16]. The higher proportion of chronic lesions in older patients was also found in a study of IgAN in children [22].

This relation was not found in our study. However, older patients had a poorer prognosis than younger patients. Older patients seem to be closer to patients with IgAN and this may explain their poorer prognosis.

To summarize, the older the patient and the longer the interval to biopsy after initial nephritis, the more chronic lesions are found, which is associated to poor prognosis.

However, focusing on patients with chronic lesions, $40 \%$ had their biopsy done after less than 1 month and 25\% even within less than 10 days after nephritis onset (Figure 2). This suggests 
that a short delay to biopsy does not necessarily prevent chronic lesions in all patients because they are present since disease onset.

This particular group of patients with chronic lesions had a worse prognosis despite an early biopsy. Therefore, if the delay after initial nephritis is similar, the nature of the disease in these particular patients may be different. These patients, with “cold” histological parameters seem to be closer to IgAN. Indeed, in an analyses of 265 cases, a working group of the International IgA Nephropathy Network and the Renal Pathology Society found GS in more than $75 \%$ and IF/TA in more than $85 \%$ of patients and conversely EP in only $40 \%$ of patients [15].

In our study, EP was not associated to poor prognosis. EP was detected in $90 \%$ of patients, which could explain the difficulty to correlate EP with renal prognosis. A better quantification of EP might have improved the interpretation of this parameter. For example, no difference is made between segmental EP and diffuse EP. Like in many other studies [6,7,23], the presence of crescents was not associated to poor prognosis. The relatively short follow-up period could explain this result. Indeed, cellular crescents become fibrous crescents and provoke hyperfiltration lesions via nephron loss. These hyperfiltration lesions may have biological consequences (in terms of increased serum creatinine) only after a couple a years. This is particularly true in children as their functional reserve is higher than in adults.

This result can also illustrate the positive impact of steroid treatment, as the most severe histological forms are often treated more aggressively and those pathological findings (EP and crescents) would be improved by the appropriate therapy.

A great proportion of patients received steroids at IgAVN onset (88\%) and this proportion was similar between patients with good or poor outcome. However, only $10 \%$ of patients did not receive steroid treatment and these patients probably had a mild clinical and histological presentation. This could explain the difficulty to analyse the positive steroid effect on renal 
outcome in a retrospective study. Generally, steroid efficiency is difficult to highlight in IgAVN and meta-analysis are still not in favour of their use [1]. However, we showed in our study that a majority of clinicians use steroids in any type of initial clinical or histological presentation. Median cumulative steroid dose is rather high in our study (3990 mg/m²). The question of steroid efficiency in IgAVN needs to be clarified, because even such a high dosage was not able to prevent persistent renal disease in $30 \%$ of patients.

In our study, the use of ACEi/ARBs alone or in association with steroids was higher in patients not in remission. This was probably due to an indication bias of ACEi/ARBs. Those patients who had a persistent proteinuria after steroids therapy received ACEi/ARBs in order to decrease the persistent proteinuria. Thus, the most severe patients were treated with

\section{ACEi/ARBs.}

Proteinuria at baseline was not correlated to renal prognosis in our study. A lot of other studies did not identify any link between initial proteinuria and renal prognosis [6,13,24]. Therefore, it seems that correlation between histological and biological parameters at IgAVN baseline rather bad. Indeed, patients without crescents have a very heterogeneous clinical presentation as previously reported [25,26]. This lack of correlation between initial proteinuria and histological lesions could explain the difficulty to identify proteinuria as an IgAVN prognostic factor. Another explanation is that patients with a higher proteinuria were probably more often treated with corticosteroids, which may explain their better prognosis due to a more aggressive treatment.

In our study, age at onset was associated with poor prognosis in univariate analysis. This result has been found in several studies [13,26,27]. Initial eGFR was different between patients with good prognosis and those with persistent proteinuria. However, initial eGFR was in the normal range in both groups, so that the difference seems to be difficult to interpret. 
There are some limitations in our study: It was a retrospective study and patients enrolled had a different treatment. The follow up can be considered as too short to precisely highlight persistent chronic disease related to hyperfiltration lesions. The histopathological evaluation of the biopsy report was not standardized and histological parameters were not read by one pathologist.

In conclusion, $30 \%$ of children with IgAVN presented a persistent renal disease at the end of a 3-year follow-up. Chronic histological lesions, which may be present at disease onset, but not EP or crescents are associated with a bad prognosis and should be evaluated in IgAVN histological classification. Crescents were not associated with poor outcome, presumably due to more aggressive treatment and its efficiency. The subset of patients which presents with histological features of chronic disease at disease onset seems to have a clinical course closer to IgAN.

\section{References}

1. Chartapisak W, Opastirakul S, Hodson EM, Willis NS, Craig JC (2009) Interventions for preventing and treating kidney disease in Henoch-Schönlein Purpura (HSP). In: The Cochrane Collaboration (ed) Cochrane Database of Systematic Reviews. John Wiley \& Sons, Ltd, Chichester, UK

2. Stewart M, Savage JM, Bell B, McCord B (1988) Long term renal prognosis of HenochSchönlein purpura in an unselected childhood population. Eur J Pediatr 147:113-115

3. Ronkainen J, Ala-Houhala M, Huttunen NP, Jahnukainen T, Koskimies O, Ormälä T, Nuutinen M (2003) Outcome of Henoch-Schoenlein nephritis with nephrotic-range proteinuria. Clin Nephrol 60:80-84

4. Goldstein AR, White RH, Akuse R, Chantler C (1992) Long-term follow-up of childhood Henoch-Schönlein nephritis. Lancet Lond Engl 339:280-282

5. Tudorache E, Azema C, Hogan J, Wannous H, Aoun B, Decramer S, Deschênes G, Ulinski T (2015) Even mild cases of paediatric Henoch-Schönlein purpura nephritis show significant long-term proteinuria. Acta Paediatr Oslo Nor 1992 104:843-848. https://doi.org/10.1111/apa.12723 
6. Coppo R, Mazzucco G, Cagnoli L, Lupo A, Schena FP (1997) Long-term prognosis of Henoch-Schönlein nephritis in adults and children. Italian Group of Renal Immunopathology Collaborative Study on Henoch-Schönlein purpura. Nephrol Dial Transplant Off Publ Eur Dial Transpl Assoc - Eur Ren Assoc 12:2277-2283

7. Soylemezoglu O, Ozkaya O, Ozen S, Bakkaloglu A, Dusunsel R, Peru H, Cetinyurek A, Yildiz N, Donmez O, Buyan N, Mir S, Arisoy N, Gur-Guven A, Alpay H, Ekim M, Aksu N, Soylu A, Gok F, Poyrazoglu H, Sonmez F, Turkish Pediatric Vasculitis Study Group (2009) Henoch-Schönlein nephritis: a nationwide study. Nephron Clin Pract 112:c199-204. https://doi.org/10.1159/000218109

8. Davin JC, Weening JJ (2001) Henoch-Schönlein purpura nephritis: an update. Eur J Pediatr 160:689-695

9. A Working Group of the International IgA Nephropathy Network and the Renal Pathology Society, Cattran DC, Coppo R, Cook HT, Feehally J, Roberts ISD, Troyanov S, Alpers CE, Amore A, Barratt J, Berthoux F, Bonsib S, Bruijn JA, D’Agati V, D’Amico G, Emancipator S, Emma F, Ferrario F, Fervenza FC, Florquin S, Fogo A, Geddes CC, Groene H-J, Haas M, Herzenberg AM, Hill PA, Hogg RJ, Hsu SI, Jennette JC, Joh K, Julian BA, Kawamura T, Lai FM, Leung CB, Li L-S, Li PKT, Liu Z-H, Mackinnon B, Mezzano S, Schena FP, Tomino Y, Walker PD, Wang H, Weening JJ, Yoshikawa N, Zhang H (2009) The Oxford classification of IgA nephropathy: rationale, clinicopathological correlations, and classification. Kidney Int 76:534-545. https://doi.org/10.1038/ki.2009.243

10. Kim CH, Lim BJ, Bae YS, Kwon YE, Kim YL, Nam KH, Park KS, An SY, Koo HM, Doh FM, Lee MJ, Oh HJ, Yoo T-H, Kang S-W, Choi KH, Jeong HJ, Han SH (2014) Using the Oxford classification of IgA nephropathy to predict long-term outcomes of Henoch-Schönlein purpura nephritis in adults. Mod Pathol Off J U S Can Acad Pathol Inc 27:972-982. https://doi.org/10.1038/modpathol.2013.222

11. Goldstein AR, White RH, Akuse R, Chantler C (2010) EULAR/PRINTO/PRES criteria for Henoch-Schonlein purpura, childhood polyarteritis nodosa, childhood Wegener granulomatosis and childhood Takayasu arteritis: Ankara 2008. Part II: Final classification criteria. Ann Rheum Dis 69:798-806. https://doi.org/10.1136/ard.2009.116657

12. Goldstein AR, White RH, Akuse R, Chantler C (1992) Long-term follow-up of childhood Henoch-Schönlein nephritis. Lancet Lond Engl 339:280-282

13. Edström Halling S, Söderberg MP, Berg UB (2010) Predictors of outcome in HenochSchönlein nephritis. Pediatr Nephrol Berl Ger 25:1101-1108. https://doi.org/10.1007/s00467-010-1444-y

14. Mir S, Yavascan O, Mutlubas F, Yeniay B, Sonmez F (2007) Clinical outcome in children with Henoch-Schönlein nephritis. Pediatr Nephrol Berl Ger 22:64-70. https://doi.org/10.1007/s00467-006-0278-0

15. A Working Group of the International IgA Nephropathy Network and the Renal Pathology Society, Cattran DC, Coppo R, Cook HT, Feehally J, Roberts ISD, Troyanov S, Alpers CE, Amore A, Barratt J, Berthoux F, Bonsib S, Bruijn JA, D’Agati V, 
D’Amico G, Emancipator S, Emma F, Ferrario F, Fervenza FC, Florquin S, Fogo A, Geddes CC, Groene H-J, Haas M, Herzenberg AM, Hill PA, Hogg RJ, Hsu SI, Jennette JC, Joh K, Julian BA, Kawamura T, Lai FM, Leung CB, Li L-S, Li PKT, Liu Z-H, Mackinnon B, Mezzano S, Schena FP, Tomino Y, Walker PD, Wang H, Weening JJ, Yoshikawa N, Zhang H (2009) The Oxford classification of IgA nephropathy: rationale, clinicopathological correlations, and classification. Kidney Int 76:534-545. https://doi.org/10.1038/ki.2009.243

16. Hennies I, Gimpel C, Gellermann J, Möller K, Mayer B, Dittrich K, Büscher AK, Hansen M, Aulbert W, Wühl E, Nissel R, Schalk G, Weber LT, Pohl M, Wygoda S, Beetz R, Klaus G, Fehrenbach H, König S, Staude H, Beringer O, Bald M, Walden U, von Schnakenburg C, Bertram G, Wallot M, Häffner K, Wiech T, Hoyer PF, Pohl M, German Society of Pediatric Nephrology (2018) Presentation of pediatric HenochSchönlein purpura nephritis changes with age and renal histology depends on biopsy timing. Pediatr Nephrol Berl Ger 33:277-286. https://doi.org/10.1007/s00467-017-37941

17. (2012) Chapter 11: Henoch-Schönlein purpura nephritis. Kidney Int Suppl 2:218-220. https://doi.org/10.1038/kisup.2012.24

18. Niaudet P, Habib R (1998) Methylprednisolone pulse therapy in the treatment of severe forms of Schönlein-Henoch purpura nephritis. Pediatr Nephrol Berl Ger 12:238-243

19. Davin J-C, Coppo R (2013) Pitfalls in recommending evidence-based guidelines for a protean disease like Henoch-Schönlein purpura nephritis. Pediatr Nephrol 28:18971903. https://doi.org/10.1007/s00467-013-2550-4

20. Kim CH, Lim BJ, Bae YS, Kwon YE, Kim YL, Nam KH, Park KS, An SY, Koo HM, Doh FM, Lee MJ, Oh HJ, Yoo T-H, Kang S-W, Choi KH, Jeong HJ, Han SH (2014) Using the Oxford classification of IgA nephropathy to predict long-term outcomes of Henoch-Schönlein purpura nephritis in adults. Mod Pathol Off J U S Can Acad Pathol Inc 27:972-982. https://doi.org/10.1038/modpathol.2013.222

21. Inagaki K, Kaihan AB, Hachiya A, Ozeki T, Ando M, Kato S, Yasuda Y, Maruyama S (2018) Clinical impact of endocapillary proliferation according to the Oxford classification among adults with Henoch-Schönlein purpura nephritis: a multicenter retrospective cohort study. BMC Nephrol 19:208. https://doi.org/10.1186/s12882-0181009-z

22. Shima Y, Nakanishi K, Hama T, Mukaiyama H, Togawa H, Hashimura Y, Kaito H, Sako M, Iijima K, Yoshikawa N (2012) Validity of the Oxford classification of IgA nephropathy in children. Pediatr Nephrol Berl Ger 27:783-792. https://doi.org/10.1007/s00467-011-2061-0

23. Ronkainen J, Nuutinen M, Koskimies O (2002) The adult kidney 24 years after childhood Henoch-Schönlein purpura: a retrospective cohort study. Lancet Lond Engl 360:666-670. https://doi.org/10.1016/S0140-6736(02)09835-5

24. Butani L, Morgenstern BZ (2007) Long-term outcome in children after HenochSchonlein purpura nephritis. Clin Pediatr (Phila) 46:505-511. https://doi.org/10.1177/0009922806298896 
25. Halling SFE, Söderberg MP, Berg UB (2005) Henoch Schönlein nephritis: clinical findings related to renal function and morphology. Pediatr Nephrol Berl Ger 20:46-51. https://doi.org/10.1007/s00467-004-1650-6

26. Delbet JD, Hogan J, Aoun B, Stoica I, Salomon R, Decramer S, Brocheriou I, Deschênes G, Ulinski T (2017) Clinical outcomes in children with Henoch-Schönlein purpura nephritis without crescents. Pediatr Nephrol Berl Ger 32:1193-1199. https://doi.org/10.1007/s00467-017-3604-9

27. Coppo R, Andrulli S, Amore A, Gianoglio B, Conti G, Peruzzi L, Locatelli F, Cagnoli L (2006) Predictors of outcome in Henoch-Schönlein nephritis in children and adults. Am J Kidney Dis Off J Natl Kidney Found 47:993-1003.

https://doi.org/10.1053/j.ajkd.2006.02.178 


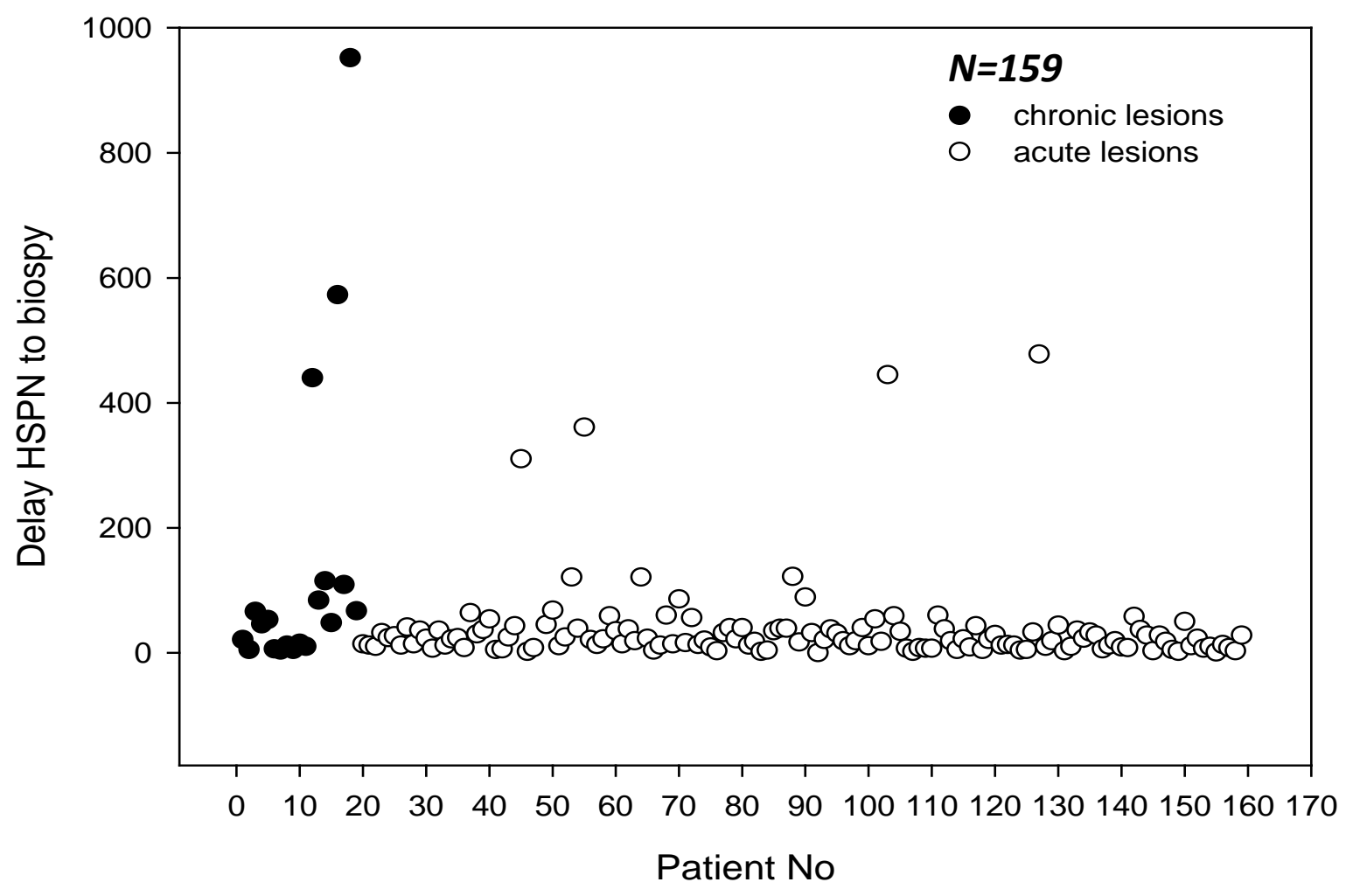

Figure 1. histological lesions depending on delay between HSPN and biopsy 
Table 1

Patients $n=159$

\begin{tabular}{ll}
\hline Baseline characteristics & \\
\hline Girls $n$ (\%) & $74(47 \%)$ \\
Boys $n$ (\%) & $85(53 \%)$ \\
Age at onset on HSPN year (QI-QS) & 7.6 years (5.8-9.5). \\
Duration HSP $\rightarrow$ RI day (QI-QS) & 17 days (6-32). \\
Duration HSPN $\rightarrow$ biopsy day (QI-QS) & $21(10-39)$ \\
GFR mI/min/1,73m2 (QI-QS) & $110(87.9-130.4)$ \\
Proteinuria mg/L (QI-QS) & $2820(1440-5000)$ \\
Protéinuria/créatininuria mg/mmol (QI-QS) & $330(180-630)$ \\
Albumin g/I (QI-QS) & 32 g/L (27-37). \\
Nephrotic syndrome & $31(19 \%)$ \\
HTA & $31(19 \%)$ \\
\hline Treatment & \\
\hline Oral corticosteroids, $n$ (\%) & $141(88 \%)$ \\
Methylprednisolone pulse, $n$ (\%) & $81(51 \%)$ \\
No corticosteroids, $n$ (\%) & $18(11 \%)$ \\
ACEi/ARBs, $n$ (\%) & $119(75 \%)$ \\
ACEi/ARBs alone, $n$ (\%) & $9(6 \%)$ \\
Oral corticosteroids alone, $n$ (\%) & $31(19 \%)$ \\
Oral corticosteroids + ACEi/ARBs, $n$ (\%) & $110(69 \%)$ \\
Another immunosuppressive agent, $n$ (\%) & $14(9 \%)$ \\
\hline Histological characteristics & \\
\hline Glomeruli (QI-QS) & $17(13-24)$ \\
Mesangial proliferation $n$ (\%) & $129(81 \%)$ \\
Endocappilary proliferation $n$ (\%) & $136(86 \%)$ \\
Cellular crescents $n$ (\%) & $78(49 \%)$ \\
Acute tubulointerstitial lesions $n$ (\%) & $34(21 \%)$ \\
Fibrous crescents $n$ (\%) & $6(4 \%)$ \\
Glomerular sclerosis $n$ (\%) & $10(6 \%)$ \\
IF/TA $n$ (\%) & $12(7 \%)$ \\
Chronic lesions $n$ (\%) & $19(12 \%)$ \\
& \\
Table 1: Baseline characteristics of the population. & \\
QI = lower quartile (25th percentile) & \\
QS = upper quartile (75th percentile) & \\
RI renal involvement & \\
IF/TA = interstitial fibrosis and tubular atrophy & \\
& \\
\hline & \\
\hline
\end{tabular}




\begin{tabular}{lll}
\cline { 1 - 2 } $\begin{array}{l}\text { Remission } \\
n=112\end{array}$ & $\begin{array}{l}\text { No remission } \\
n=47\end{array}$ & $p$ \\
\cline { 2 - 2 } $54 / 58$ & $20 / 27$ & 0.516 \\
$7.2(5,6-8,8)$ & $8.4(6.5-12.2)$ & $\underline{\mathbf{0 . 0 0 3}}$ \\
$115(94.64-138.3)$ & $99.9(79.1-112.9)$ & $\underline{\mathbf{0 . 0 2}}$ \\
$16.5(6-31.7)$ & $17(8-33)$ & 0.64 \\
$20.5(10-38)$ & $22.5(9.5-55)$ & 0.35 \\
$35.6(20-58.5)$ & $52.6(18.2-93.7)$ & 0.053 \\
$367.5(182.5-615.75)$ & $300(180-637)$ & 0.46 \\
& & \\
$100 / 112(89 \%)$ & $41 / 47(87 \%)$ & 0.6 \\
$57 / 112(50 \%)$ & $24 / 47(51 \%)$ & 0.98 \\
$76 / 112(68 \%)$ & $43 / 47(91 \%)$ & $\underline{\mathbf{0 . 0 0 1}}$ \\
$29 / 112(26 \%)$ & $2 / 47(4 \%)$ & $\underline{\mathbf{0 . 0 0 2}}$ \\
$71 / 112(63 \%)$ & $39 / 47(82 \%)$ & $\underline{\mathbf{0 . 0 1 5}}$ \\
$5 / 112(4 \%)$ & $5 / 47(10 \%)$ & 0.146
\end{tabular}

Table 2. Analysis of clinical risk factors and treatment associated to the remission $R I=$ renal involvement $H S P=$ Henoch schonlein purpura HSPN = Henoch schonlein purpura nephritis

Remission No remission

\begin{tabular}{llll} 
Risk factors & $n=112$ & $n=47$ & $p$ \\
\hline Endocapillary proliferation & $93 / 112(83 \%)$ & $43 / 48(89 \%)$ & 0.17 \\
Cellular crescents & $54 / 112(48 \%)$ & $26 / 47(55 \%)$ & 0.41 \\
Acute tubulointerstitial lesions & $21 / 112(18 \%)$ & $13 / 47(27 \%)$ & 0.189 \\
Glomerular sclerosis & $4 / 112(4 \%)$ & $6 / 47(13 \%)$ & $\underline{\mathbf{0 . 0 2 8}}$ \\
IF/TA & $4 / 112(4 \%)$ & $8 / 47(17 \%)$ & $\underline{\mathbf{0 . 0 0 9}}$ \\
Chronic lesions & $7 / 112(6 \%)$ & $12 / 47(26 \%)$ & $\underline{\underline{\mathbf{0 0 0 1}}}$
\end{tabular}

Table 3. Analysis of histological risk factors associated to the remission IF/TA = interstitial fibrosis and tubular atrophy 


\section{Chronic lesions $\quad$ Acute lesions}

\begin{tabular}{llll} 
Risk factors & $n=19$ & $n=140$ & $p$ \\
\hline $\begin{array}{l}\text { Duration HSPN } \rightarrow \text { biopsy day (QI- } \\
\text { QS) }\end{array}$ & $48(10-109)$ & $21(10-37)$ & $\underline{\mathbf{0 . 0 4 6}}$ \\
Age year (QI-QS) & $7.5(5.7-11.1)$ & $7.6(5.8-9.5)$ & 0.63 \\
Duration HSP $\rightarrow$ RI day (QI-QS) & $28(5-91)$ & $16(6,25-30,7)$ & 0.185 \\
GFR ml/min/1,73m2 (QI-QS) & $102,5(80-119)$ & $113(89-133)$ & 0.19 \\
Proteinuria mg/mmol (QI-QS) & $280(120-730)$ & $340(192-620)$ & 0.37 \\
Oral corticosteroids $n(\%)$ & $17(89 \%)$ & $124(88 \%)$ & 0.97
\end{tabular}

Table 4. Analysis of clinical risk factors associated to the presence of chronic lesions $R I=$ renal involvement $H S P=$ Henoch schonlein purpura $H S P N=$ Henoch schonlein purpura nephritis

\begin{tabular}{|c|c|c|c|c|}
\hline \multirow[b]{2}{*}{ Risk factors } & \multicolumn{2}{|c|}{ Remission No remission } & $\begin{array}{l}\text { Univariate } \\
\text { analysis }\end{array}$ & $\begin{array}{l}\text { Multivariate } \\
\text { analysis }\end{array}$ \\
\hline & $n=95$ & $n=40$ & $p$ & OR $95 \% \mathrm{Cl}$ \\
\hline Age year (QI-QS) & $8(6.4-9.5)$ & $8.5(6.5-12.3)$ & 0.002 & $0.82(0.72-0.95)$ \\
\hline Cellular crescents $n(\%)$ & 49 (51\%) & $22(55 \%)$ & 0.71 & \\
\hline Endocapillary proliferation $n(\%)$ & $81(85 \%)$ & $36(90 \%)$ & 0.46 & \\
\hline Proteinuria $\mathrm{mg} / \mathrm{mmol}$ (QI-QS) & $357(180-630)$ & $275(147-564)$ & 0.56 & $1.0(0.99-1.001)$ \\
\hline duration HSPN $\rightarrow$ biopsy day (QI-QS) & $19(9-38)$ & $31(10-64)$ & 0.03 & $0.99(0.99-1.002)$ \\
\hline Chronic lesions $n(\%)$ & $7(7.3 \%)$ & $10(25 \%)$ & 0.005 & $3.84(1.18-12.44)$ \\
\hline
\end{tabular}

Table 5 Analysis of risk factors associated to the remission one year after IgAVN diagnosis HSPN = Henoch schonlein purpura nephritis 